\title{
ACORDOS E REGRAS NORTEADORAS DO COMÉRCIO INTERNACIONAL: DA RODADA URUGUAI À POLÍTICA DE COMÉRCIO EXTERIOR BRASILEIRA
}

\author{
Heberto Olímpico Costa \\ E-mail: heberto_costa@yahoo.com.br \\ Graduado em Comércio Exterior pelo IFRN. Bacharel em Direito pela UFRN. Especialista \\ em Direito Administrativo e Gestão Pública pela UnP/RN. Especializando em Ciências Penais \\ pela Universidade Anhaguera/SP. E-mail: heberto_costa@yahoo.com.br \\ Elisângela Cabral de Meireles \\ Graduada em Ciências Econômicas-UFRN, esp. em Economia Regional, Comércio Exterior e \\ Globalização-UFRN, mestre em Administração (Gestão e Políticas Públicas) UFRN, \\ Professora do IFRN (Comércio Exterior e Economia) e Professora Orientadora da Base de \\ Pesquisa "Análise do Mercado Exportador do Rio Grande do Norte (IFRN). \\ E-mail- elisangela@ cefetrn.br
}

\section{RESUMO}

Este trabalho objetiva compreender o cenário norteador do Comércio Internacional após 1986, com a Rodada Uruguai e sua influência na política de Comércio Exterior do Brasil. Investigase os principais acordos e regras norteadoras do Comércio Internacional; as ações realizadas no âmbito brasileiro para a política de Comércio Exterior; a relação entre a proposta mundial de comércio e a que, efetivamente, o Brasil realiza. $O$ estudo foi realizado, por meio de levantamento bibliográfico e documental, tomando-se como contexto o Brasil inserido no mercado internacional, delimitado pelo recorte temporal pós-Rodada do Uruguai, realizada entre 1986 e 1994, estendendo-se até o ano de 2006, no que concerne aos reflexos, advindos dessa Rodada de Negociações Internacionais sobre a Política Brasileira de Comércio Exterior. A intensificação dos movimentos de Globalização, de produção e internacionalização dos fluxos de capitais significa um mundo de crescente interdependência econômica entre as nações, cuja regulação tem suscitado questões quanto ao papel reservado ao Estado, condutor dos ditames político-econômicos, frente às instituições internacionais criadas, a partir da Conferência de Bretton Woods em 1944. Do trabalho concluiu-se quais os desafios da política de comércio exterior brasileira para os próximos anos: participação mais atuante no âmbito da Organização Mundial de Comércio, integração do Mercosul na Área de Livre Comércio das Américas e na União Européia. Tais desafios requerem dos atores da sociedade (Governos, Empresas, Trabalhadores) preparação para avaliar os impactos de cada uma das regras do comércio em negociação, não só para as políticas econômicas do país, mas também para o futuro das atividades das empresas.

PALAVRAS-CHAVE: Acordos, Regras, Comércio Internacional e Política. 


\title{
AGREEMENTS AND RULES GUIDING THE INTERNATIONAL TRADE: THE URUGUAY ROUND ON THE POLICY FOREIGN TRADE BRAZIL
}

\begin{abstract}
The goal of this work is to comprehend the guiding scenery of the International Trade that emerged after 1986 with the Uruguay Round and that influenced the policy of Exterior Trade of Brazil. It was enquired the main deals and guiding rules of the International Trade; the actions accomplished in Brazil towards policy of Exterior Trade; and the connection between the worldwide proposal of trade and the one that, effectively, was accomplished by Brazil. The study was based on bibliographic and documental collection, taking for context the country of Brazil inserted in the international trade, marked out by the recorte temporal postUruguay Round, realized between 1986 and 1994, extending to the year of 2006, concerning to the reflexes, brought by this Round of International Negotiations. The increase of the Globalization movements, of production and internationalization of the fluxes of capitals means a world of increasing economic interdependency among the nations, whose regulation has generated questions about the role reserved to the Government, manager of the political and economic ditames, about the international institutions created since the Conference of Bretton Woods in 1944. This work it can be concluded which are the challengesof the Brazilian policy of exterior trade for the next years: They are a more active participation in the WTO, the Mercosul's integration of the in the Alca and Mercosul's integration in the European Union. Such challenges require from the actors of the society (governments, enterprises, workers) preparation to evaluate the impacts of each one of the trade rules in negotiation, not only to the economic policies of the country, but also to the future of the activity of the entreprises.
\end{abstract}

KEY-WORDS: Deals, Rules, International Trade and Policy.

\section{INTRODUÇÃO}

O presente trabalho objetiva compreender o cenário norteador do Comércio Internacional que surgiu após 1986, com a Rodada Uruguai ${ }^{1}$ e influenciou a política de Comércio Exterior do Brasil. Inicialmente, identifica os principais acordos e regras norteadoras do atual Comércio Internacional, partindo de um breve resgate histórico da criação do Acordo Geral de Tarifas e Comércio (GATT) para, em seguida, aprofundar a discussão com a "evolução" das rodadas de negociações do GATT. Posteriormente, evidencia as características das ações realizadas no âmbito brasileiro para a política de Comércio Exterior, avaliando a relação entre a proposta mundial de Comércio Internacional e a que, efetivamente, o Brasil realiza.

Atualmente, verifica-se uma relação amiúde entre as relações econômicas internacionais e a Globalização, com implicações de natureza política, econômica, comercial e também, cultural. O fenômeno da Globalização, presenciado nas últimas décadas, possibilita florescer o debate sobre a soberania dos Estados-Nações, diante das forças dos países desenvolvidos

\footnotetext{
${ }^{1}$ Uma rodada constitui-se em um conjunto de negociações comerciais entre países, que normalmente leva o nome do local onde se inicia. A Rodada Uruguai, iniciada em 1986, na cidade de Punta del Este e terminada formalmente em 1993, sendo assinada em abril de 1994 pelas partes, na cidade de Marraqueche, foi a oitava rodada do GATT, sendo a mais ambiciosa e complexa das negociações já estabelecidas.
} 
com preponderância comercial e os países emergentes, os quais têm a condução de suas políticas e estratégias ditadas pelos organismos internacionais.

Essa relação desigual de comércio afeta diretamente a soberania dos países periféricos, visto que a soberania nacional é o fundamento político e jurídico da autoridade do Estado. É ela, que respalda o domínio sobre determinado território e permite, aos representantes de um país, a última palavra sobre qualquer assunto.

Discorrendo sobre o tema Brigagão (1998, p. 22) ensina que:

[...] a Globalização, porém, não irá extinguir a soberania nacional e apagar o Estado do mapa-múndi, pois ele continuará existindo com funções importantes, incluindo o exercício da soberania territorial. E o processo de globalização pode mesmo fortalecer a soberania estatal, incentivando outras formas de atuação do Estado: o Estado-regulamentador, o Estado-mediador etc.

O processo de mundialização do capitalismo, a Globalização, ensejou a configuração de um mercado mundial e a existência de atores e centros de poder supranacionais. Essas transformações afetaram o papel do Estado moderno como centro de poder e como protagonista da política internacional. Nesse sentido, a Globalização não eliminou a atuação dos Estados nacionais, porém impôs uma redefinição do seu papel frente às suas respectivas sociedades e às relações políticas internacionais.

A supranacionalidade pressupõe uma ampliação do conceito tradicional de nacionalidade ${ }^{2}$, pois a constituição de um bloco econômico sobrepõe o próprio conceito moderno de Estado ${ }^{3}$, visto que conjuga interesses diversos de países em um conjunto de políticas e estratégias comuns.

Torna-se claro que a nova ordem mundial, que emergiu a partir da queda do Muro de Berlim, contribuiu para o reordenamento geopolítico e econômico mundial, uma vez que aprofundou o processo de globalização, favorecendo a consolidação e a supremacia de blocos econômicos supranacionais, propiciando o surgimento de um novo papel para o Estado, muito diferente do modelo clássico, mercantilista e interventor.

Essa nova ordem globalizada colocou em evidência a crise do Estado no que diz respeito ao seu papel de interventor na esfera econômica, visto que na ótica neoliberal vigente na atualidade a economia tende a se auto-regular.

O Brasil assinou, em dezembro de 1993, a Ata Final da Rodada, que propôs o Acordo para criação da Organização Mundial de Comércio (OMC) e participou de todas as negociações do GATT, defendendo os princípios da liberalização do comércio internacional, considerado pela ótica brasileira como fator básico na condução de política desenvolvimentista do País, atuando em favor da remoção dos obstáculos ao comércio exterior, principalmente, nas últimas décadas, em questões relativas a problemática dos subsídios agrícolas europeus e

\footnotetext{
${ }^{2}$ Tradicionalmente, entende-se nacionalidade como o vínculo jurídico-político que liga um indivíduo a um certo e determinado Estado, fazendo deste indivíduo um componente do povo, da dimensão pessoal deste Estado, capacitando-o a exigir sua proteção e sujeitando-se ao cumprimento de deveres impostos.

3 Trata-se do Estado Neoliberal, que prega um modelo de Estado mínimo, compreendendo reformas de dimensões administrativas, patrimonial e de política econômica, caracterizadas por demissões, privatizações e retirada do Estado da Economia.
} 
norte-americanos, bem como na questão dos chamados "novos temas" relacionados à propriedade intelectual e a inclusão do comércio de serviço no âmbito do GATT.

Diante do exposto, a origem do problema norteador da pesquisa partiu da necessidade de compreensão da dinâmica do Comércio Internacional, das relações entre países, enfocando principalmente, tal influência sobre a política brasileira de relações internacionais ante as regras norteadoras de comércio da atualidade. Entender como acontecem às políticas e estratégias do Brasil no paradoxo do Multilateralismo Comercial e do protecionismo dos países preponderantes de mercado.

Nesse contexto, o referido trabalho se propôs responder à seguinte problemática: como o Multilateralismo do discurso, que se formou após a Rodada Uruguai tem influenciado a Política Brasileira de Comércio Exterior até a atualidade?

O estudo foi realizado, por meio de levantamento bibliográfico e documental, tomando-se como contexto o Brasil inserido no Mercado Internacional, delimitado pelo recorte temporal pós-Rodada do Uruguai, estendendo-se até o ano de 2006, no que concerne aos reflexos, advindos dessa Rodada de Negociações Internacionais sobre a Política de Comércio Exterior Brasileira.

Para maior compreensão do assunto, o presente trabalho divide-se em quatro seções, sendo esta introdução, a primeira delas. Na segunda seção, procura-se abordar Acordos e Regras norteadoras do comércio internacional, em especial os frutos da Rodada Uruguai. Na terceira seção faz-se uma reflexão a respeito da política de comércio exterior brasileira, suas principais características, perspectivas e avanços no cenário internacional. Por fim, na última seção faz-se as considerações finais.

\section{ACORDOS E REGRAS NORTEADORAS DO COMÉRCIO INTERNACIONAL: Breve histórico do surgimento das Regras e Acordos do Comércio Internacional}

Após a Segunda Guerra Mundial, vários países decidiram regular as relações econômicas internacionais, não somente com o objetivo de melhorar a qualidade de vida de seus cidadãos, mas também por entenderem que os problemas econômicos influíam seriamente nas relações entre os Governos. Para regular aspectos financeiros e monetários, foram criados o Banco Mundial (BIRD) e o Fundo Monetário Internacional (FMI), e no âmbito comercial, foi discutida a criação da Organização Internacional do Comércio (OIC), que funcionaria como uma agência especializada das Nações Unidas.

Em 1946, visando impulsionar a liberalização comercial, combater práticas protecionistas adotadas desde a Década de 30, vinte e três países, posteriormente denominados fundadores, iniciaram negociações, visando reduções tarifárias. Essa primeira rodada de negociações resultou em 45.000 concessões e o conjunto de normas e concessões tarifárias estabelecido passou a ser denominado Acordo Geral sobre Tarifas e Comércio - GATT.

Os membros fundadores, juntamente com outros países, formaram um grupo que elaborou o projeto de criação da OIC, sendo os Estados Unidos, um dos países mais atuantes no convencimento da idéia do liberalismo comercial, regulamentado em bases multilaterais. $\mathrm{O}$ foro de discussões, que se estendeu de novembro de 1947 a março de 1948, ocorreu em 
Havana, Cuba, e culminou com a assinatura da Carta de Havana, na qual constava a criação da OIC. Esse projeto era ambicioso, pois, além de estabelecer disciplinas para o comércio de bens, continha normas sobre emprego, práticas comerciais restritivas, investimentos estrangeiros e serviços.

Apesar do papel preponderante desempenhado pelos Estados Unidos nessas negociações, questões políticas internas levaram o país a anunciar, em 1950, o não encaminhamento do projeto ao Congresso, para sua ratificação. Porém, sem a participação dos Estados Unidos, a criação da Organização Internacional do Comércio fracassou. Assim, o GATT, um acordo criado para regular provisoriamente as relações comerciais internacionais, foi o instrumento que, de fato, regulamentou, por mais de quatro décadas, as relações comerciais entre os países.

A estrutura original do GATT dividia-se em três partes: a primeira consistia nos principais fundamentos do processo de liberação, que se baseiam na cláusula de nação mais favorecida e o conceito de reciprocidade.

De acordo com Thostensen (2001, p. 33):

\begin{abstract}
É a mais importante das regras e dá caráter multilateral ao GATT, em detrimento do caráter bilateral, visto que estabelece que toda vantagem, favor, privilégio ou imunidade afetando direitos aduaneiros ou outras taxas que são concedidos a uma parte contratante, devem ser acordados imediatamente e incondicionalmente a produtos similares comercializados com qualquer outra parte contratante.
\end{abstract}

A segunda parte contém a base normativa do acordo, determina a lista dos produtos e das tarifas máximas que devem ser praticadas no Comércio Internacional, bem como as medidas de exceções domésticas em relação ao processo de liberalização.

A terceira parte disciplina as regras de acesso ao GATT, à negociação de tarifas e aos acordos regionais. Em 1965, foi incorporada uma nova parte que trata, exclusivamente, da questão dos países em desenvolvimento.

São essas regras básicas, negociadas dentro do Acordo Geral do GATT, que se tornaram as regras de atuação dos parceiros mundiais na área do comércio internacional. É importante salientar que o Acordo Geral apenas define os princípios, sendo a elaboração das regras do comércio para cada parte, bem como a forma de implementá-la dentro do seu território, de competência exclusiva de cada parte contratante do Acordo Geral (THOSTENSEN, 2001).

Diante do exposto, pode-se inferir que embora a taxa de crescimento econômico dependa, nos países em desenvolvimento, primeiramente das condições internas, o comércio internacional pode contribuir significativamente para o processo de desenvolvimento.

\title{
HISTÓRICO DA CRIAÇÃO E EVOLUÇÃO DO GATT
}

A partir de um tratado multilateral firmado em Genebra em 1947, na Suíça, originou-se o Acordo Geral de Tarifas e Comércio (GATT) com a finalidade de intensificar o Comércio Internacional. Os princípios básicos do GATT, de acordo com Maia (2003, p. 197), são os seguintes: "o comércio deve ser conduzido de forma não discriminatória; deve ser condenado 
o uso de qualquer restrição quantitativa e as disputas devem ser resolvidas por meio de consultas".

O GATT é o único tratado multilateral que estabelece regras para o Comércio Internacional, ao mesmo tempo, que é o principal organismo internacional para as negociações de Comércio Internacional e de resolução de disputas e controvérsias na área. Originalmente, assinado por vinte e três países, entre eles o Brasil, com o passar dos anos, o GATT foi atualizado e teve seu escopo de incidência ampliado através de alterações efetuadas como resultado de negociações levadas a efeito nas chamadas rodadas (GOYOS JR. 1994).

Desde sua origem, o GATT teve oito reuniões de negociações comerciais ${ }^{4}$. A Rodada do Uruguai foi realizada, entre 1986 e 1994, e resultou na assinatura da Ata Final da Rodada Uruguai de Negociações Multilaterais em 15 de Abril de 1994, por 117 representantes dos países participantes. O acordo criou também a Organização Mundial do Comércio (OMC), que possui o status jurídico de uma instituição internacional para regulamentação do comércio internacional, diferentemente do GATT que não possui países membros, mas países contratantes ou signatários.

Tal mudança era vital para alavancar o processo de globalização e a OMC surgiu como o instrumento ideal para impor com mais força as suas decisões e, conseqüentemente, a liberalização do comércio internacional.

Em suma, os valores apontavam para a formação de um conjunto de regras que viabilizariam a ordenação do comércio mundial em bases multilaterais e liberais e, em que, práticas restritivas e discriminatórias estariam ausentes.

Vale ressaltar, que a liberalização patrocinada pelo GATT teve papel de fundamental importância no crescimento do comércio mundial, conforme é evidenciado na figura que segue:

\section{Figura 1 - Evolução das Exportações Mundiais - 1950 a 2005}

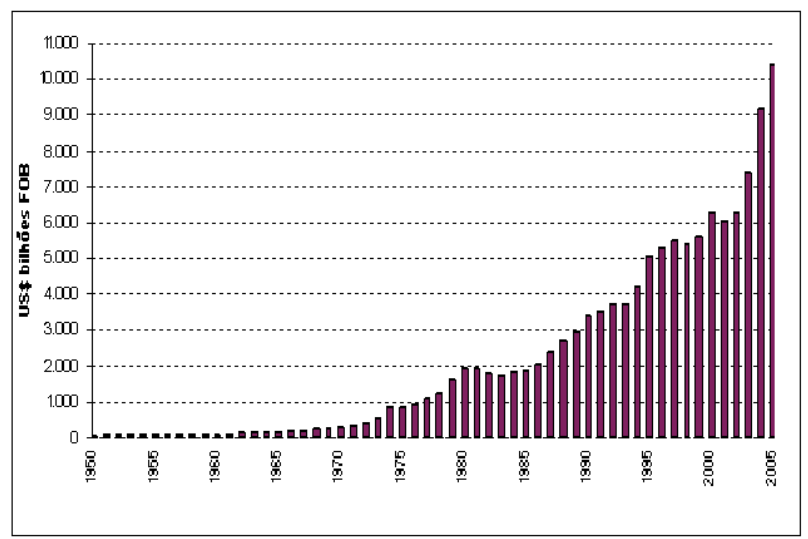

Fonte: Exportações brasileiras: SISCOMEX e SECEX; Importações brasileiras: SISCOMEX e MF/SRF (2006)

\footnotetext{
${ }^{4}$ Até os dias de hoje já foram realizadas 8 rodadas de negociação, a saber: a de Genebra (1947); Annecy (1949); Toquay (1950-1951); Genebra (1955-1956); Genebra, Rodada Dillon (1960-1961); Genebra, Rodada Kennedy (1964-1967); Genebra, Rodada Tóquio (1973-1979) e Genebra, Rodada Uruguai (1986-1994).
} 
Verifica-se na figura acima, o crescimento constante do comércio internacional, desde valores ínfimos, quando da criação do GATT, em 1947, para valores expressivos, sobretudo, com a criação da OMC, fruto da Rodada do Uruguai, em 1995, chegando a ultrapassar a cifra dos US\$ 10.000 bilhões FOB, em 2005.

\section{Rodada Uruguai ${ }^{5}$}

As restrições ao comércio e às barreiras foram sendo reduzidas, gradualmente, em lento e difícil processo de negociação. O GATT, mediante o processo de negociações de redução tarifária, contribuiu sensivelmente para estimular a expansão do comércio internacional, ainda que funcionasse de forma provisória e dentro de um reduzido âmbito de atuação.

Entretanto, nas últimas décadas surgiram fenômenos políticos e comerciais que influenciaram os rumos da economia internacional, entre eles: a) serviços e tecnologia aparecem como valores de grande importância na economia internacional, além do comércio tradicional de bens; b) forte tendência à organização em blocos comerciais; c) surgimento de novos componentes na concorrência comercial, como aspectos relacionados ao meio ambiente, normas sanitárias mais exigentes, defesa dos interesses dos consumidores; d) o pós guerra fria, que eliminou o panorama bipolar das relações internacionais, permitindo o aparecimento do multilateralismo, a globalização; d) derrocada da filosofia comunista como modelo de governo e o alargamento das fronteiras do capitalismo, principalmente no que diz respeito aos países do leste europeu.

Os países perceberam, então, que neste novo cenário internacional, a capacidade do GATT, para atuar como instrumento adequado para a administração do comércio mundial, estava se esgotando. As negociações realizadas no decorrer da Rodada Uruguai culminaram na elaboração de um novo conjunto de regras e instrumentos mais adequados à nova realidade do contexto internacional e na criação da Organização Mundial do Comércio.

\section{POLÍTICA DE COMÉRCIO EXTERIOR BRASILEIRA}

A Década de 80 foi caracterizada por dois aspectos econômicos: primeiro, pelo desenvolvimento de acordos e mecanismos de integração econômica entre países e regiões, tanto nas economias mais desenvolvidas como em desenvolvimento; segundo, pelas limitações de acesso ao comércio exterior através da utilização de barreiras não-tarifárias ${ }^{6}$ (um modo de proteger a indústria doméstica).

No Brasil, a Abertura Comercial iniciada, a partir de 1990, tenta inserir o País no cenário do Comércio Internacional. Os instrumentos utilizados passam pela formação de acordos regionais, redução tarifária e pela desregulamentação das operações de Comércio

\footnotetext{
5 A Rodada Uruguai, a mais importante das rodadas de negociações comerciais já realizadas, estabelece um novo marco jurídico para o comércio mundial, com a criação da OMC. O Brasil é um dos membros fundadores da OMC, a base jurídica e institucional do sistema multilateral de comércio desde janeiro de 1995. Com a OMC, o comércio internacional ingressou em uma nova fase, com maiores direitos e deveres para praticamente todos os países.

${ }^{6}$ Barreiras não-tarifárias são normas técnicas, administrativas e outras, bem como àquelas advindas dos cartéis internacionais, dumping e subsídios às exportações (Salvatore, 1998, p. 423).
}

Observatório - Monografias em Comércio Exterior, Ano 1, Vol. 1 
Internacional. $\mathrm{O}$ resultado imediato dessas medidas é o crescimento no volume das importações e, conseqüentemente, o aumento da concorrência para as indústrias nacionais que se vêem obrigadas a adaptar-se ao mercado. $\mathrm{O}$ aumento na qualidade e na produtividade reflete ganhos de bem-estar da população.

Com a Rodada Uruguai, iniciada em 1986, acreditava-se que o mundo caminharia para a eliminação das barreiras multilaterais, no entanto, para Gonçalves (1994, p. 96), "a conclusão da Rodada Uruguai não envolve nenhuma ruptura no sistema econômico internacional”, visto que o grande determinante das relações comerciais será a revitalização dos blocos regionais.

Nesse sentido, a política brasileira de comércio exterior é formulada e implementada estruturada em novos condicionantes externos (as regras da OMC e os compromissos no Mercosul) e internos (os esforços de ajuste fiscal) restringindo, drasticamente, as perspectivas de continuidade das políticas de exportação então vigentes, ao passo que a abertura comercial redefiniu prioridades e instrumentos no âmbito da política de importação.

A partir de meados da Década de 80, o objetivo de aumentar as exportações ganhou destaque entre as prioridades de governo, e as negociações comerciais adquiriram um peso crescente na agenda da política de comércio exterior, tornando-se, gradativamente, uma questão no debate político doméstico no País.

Uma das críticas usualmente formuladas em relação à política brasileira de comércio exterior envolve a institucionalidade da política. Falta de coordenação e superposição de atribuições e funções seria a regra no campo das políticas públicas, levando ao desperdício de esforços e recursos e a problemas de implementação dos mecanismos e políticas definidas. Na visão que se desenvolve neste trabalho, tais disfuncionalidades expressam um problema mais profundo: a política brasileira de comércio exterior, em especial na área de exportação, ainda não se adaptou a um novo quadro de condicionantes e objetivos que se consolida nos anos 90 e, como regra, o quadro institucional da política não incentiva essa adaptação, embora ela venha ocorrendo em áreas específicas, como as negociações internacionais.

Discorrendo sobre o assunto Vasquez $(2001,15)$ afirma:

O Comércio Exterior Brasileiro, carente de uma política operacional e administrativa que parametrize e oriente sua evolução e crescimento, tem sido um dos sustentáculos da economia nesses anos de recessão, colaborando com eficácia para que o PIB voltasse a ter um crescimento positivo a partir de 1993.

Mesmo diante de todas essas incertezas e incongruências operacionais no cenário brasileiro verifica-se um aumento constante nas exportações, provocando saldos crescentes na Balança Comercial, sendo reflexo, principalmente, de fatores exógenos que refletem sobre a realidade brasileira. As exportações brasileiras, em termos absolutos, com o avanço das rodadas em negociação, variaram de valores ínfimos, próximos a zero em 1950, para aproximadamente US\$ 120 bilhões FOB em 2006, representando um crescimento exponencial, como evidenciado acima.

Vale salientar, que o Brasil é visto pelos países desenvolvidos como um membro pleno, que não deve pretender receber tratamento privilegiado ou mais benéfico, ou seja, o Brasil está 
sujeito às mesmas restrições à liberdade que os países desenvolvidos, mesmo sem ter atingido um grau de desenvolvimento comparável.

Portanto, faz-se necessário possibilitar uma integração efetiva (e não apenas jurídica) do Brasil no âmbito do Comércio Internacional, de forma que as necessidades de desenvolvimento sejam atendidas, visto que tal princípio sempre foi um dos objetivos das rodadas de negociações multilaterais, que não foi diferente na Rodada Uruguai.

\section{CONSIDERAÇÕES FINAIS}

Após quase uma década de negociações multilaterais, o mundo opta por formar acordos regionais de comércio, bilaterais ou plurilaterais, com as mais variadas características e níveis de aprofundamento.

Os Acordos Regionais de Comércio tornaram-se um processo efetivo para aumentar a competitividade dos países participantes e cultivar novos mercados por meio de políticas de integração preferenciais e, por outras políticas de liberalização e de desregulamentação gradual de suas economias.

Parece claro que o Brasil, no contexto da América Latina, está envolvido em um processo de redes de acordos comerciais de convergência entre iniciativas de Acordos Regionais e SubRegionais, com preferências ao Mercosul e, de alianças menos rígidas e não exclusivas com os demais Acordos.

No entanto, as negociações com a ALCA, que prevêem uma área de livre comércio para as Américas, podem gerar disputas internas com o Mercosul e inconsistências, nas ligações do Mercosul e demais blocos que estão sendo pretendidos, uma vez que o Mercosul ainda não está consolidado e as políticas comerciais com os membros do bloco e com outros países necessita de vários ajustes.

Todavia, no que se refere às políticas do Ministério de Desenvolvimento, Indústria e Comércio (MDIC), o Brasil, procurou desenvolver diversos instrumentos, visando aumentar o nível de crescimento do setor comercial, adotando medidas de incentivo às exportações, como a Implantação do Comitê de Gestão do Comércio Exterior e a Defesa Comercial que objetivam investigar a ocorrência de dumping nas exportações para o Brasil.

Ao final do trabalho, pôde-se evidenciar o panorama em que está assentada a Política de Comércio Exterior Brasileira, bem como concluir quais os desafios para os próximos anos: participação mais atuante no âmbito da OMC, integração do Mercosul na Alca e na União Européia. Tais desafios requerem dos atores da sociedade (Governos, Empresas, Trabalhadores) preparação para avaliar os impactos de cada uma das regras do comércio em negociação, não somente para as políticas econômicas do País, mas também para o futuro das atividades das empresas. Assim, a avaliação implica no reposicionamento das ações estratégicas do Brasil no cenário internacional, que permitam uma inserção mais competitiva. 


\section{REFERÊNCIAS BILBIOGRÁFICAS}

1. ANDERSON, Prry. Balanço do neoliberalismo. In SADER, Emir \& GENTILI, Pablo., orgs. Pós-neoliberalismo: as políticas sociais e o Estado democrático. Rio de Janeiro: Paz de Janeiro, 1995.

2. BALDWIN, R. The changing nature of U.S. Trade policy since world II. In: R. Baldwin e A.O. Krueger eds. The Structure and Evolution af Recente U.S. Trade Policy. Chicago: The University of Chicago Press, 1984.

3. BHAGWATI, J. The world trading system at risk. New Jersey: Princeton University Press, 1991.

4. BOBBIO, Norberto. Estado, governo e sociedade. Para uma teoria geral da política. Rio de Janeiro: Paz e Terra, 1987.

5. BRIGAGÃO, C.; RODRIGUES, G. Globalização a olho nu: o mundo conectado. São Paulo: Moderna, 1998.

6. CAVES, Richard E., FRANKEL, Jeffrey, JONES, Ronald W. Economia internacional: comércio e transações globais. Tradução de Cecília Camargo Bartalotti, Célio Knipel Moreira. São Paulo: Saraiva, 2001.

7. CHESNAIS, François. A mundialização do capital. Tradução de Silvana Finzi Foá. São Paulo: Xanã, 1996.

8. DI SENA JÚNIOR, Roberto. O dumping e as práticas desleais de comércio exterior. Jus Navigandi, Teresina, a. 4, n. 44, ago. 2000. Disponível em: <http://jus2.uol.com.br/doutrina/texto.asp?id=768>. Acesso em: \$29 ago. 2006.

9. DIÁRIO DE NATAL. Pacto pelo desenvolvimento do Rio Grande do Norte. Natal: Encarte Especial, 2000.

10. GERMANO, José Willington. Neo-liberalismo e contexto internacional. Revista Vivência. Natal, v.7, nº 1, p. 19-32, jul/dez. 1993.

11. GONÇALVES, Reinaldo. O Brasil e o comércio internacional: transformações e perspectivas. $2^{a}$ ed. São Paulo: Contexto, 2003.

12. GONÇALVES, Reinaldo, [et al.] A nova Economia Internacional: uma perspectiva brasileira. Rio de Janeiro: Campus, 1998.

13. GRIECO, Francisco de Assis. O comércio exterior e as crises financeiras. São Paulo, Aduaneiras, 1999.

14. GOYOS JUNIOR, Durval de Noronha. A OMC e os Tratados da Rodada Uruguai. São Paulo: Observador Legal, 1994.

15. JO, Hee Moon. Introdução ao direito internacional. 2a Ed. São Paulo: LTr, 2004. 
KRUGMAN, P., OBSTFELD, M. International economics: theory and policy. Third Edition; New York: Harpers Collins College Publishers, 1994.

16. KRUGMAN, Paul R. e OBSTELD. Economia Internacional: teoria e política. São Paulo: Makron Books, 2001.

17. LOPES, J.C., ROSSETI, J. P. Economia Monetária. São Paulo: Atlas, 1998.

18. VALL, Lia. Histórico da Rodada do Uruguai do GATT. Estudos em Comércio Exterior. Vol. I, no 3 - jul/dez 1997.

19. MAIA, Jayme de Mariz. Economia internacional e comércio exterior. $8^{\mathrm{a}}$ Ed. São Paulo: Atlas, 2003.

20. MALUF, Sâmia Nagib. Administrando o comércio exterior do Brasil. São Paulo: Aduaneiras, 2000.

21. MARCONI, Marina de Andrade, LAKATOS, Eva Maria. Fundamentos da metodologia científica. São Paulo: Atlas, 2005.

22. MEIRELES, Elisângela Cabral de. Comércio Internacional: um grande negócio para todos. Disponível em: <http://www.conhecaorn.com.br/crn/comercio-exterior01.asp>. Acesso em: 8 jun 2006.

23. As multifaces da liberalização internacional do comércio. Disponível em: <http://www.conhecaorn.com.br/crn/comercio-exterior01.asp>. Acesso em: 20 jun 2006.

24. Os desafios do mercosul no comercio internacional. Disponível em: <http://www.conhecaorn.com.br/crn/comercio-exterior01.asp>. Acesso em: 8 ago 2006.

25. MINERVINI, Nicola. O exportador. Tradução de Patrizia Minervini. $4^{\mathrm{a}}$ ed. São Paulo: Prentice Hall, 2005.

26. MINISTÉRIO DO DESENVOLVIMENTO, INDÚSTRIA E COMÉRCIO EXTERIOR. Secretaria de Comércio Exterior. Departamento de Operações de Comércio Exterior. Estatísticas de Comércio Exterior. Disponível em: <www.desenvolvimento.gov.br>. Acesso em: 1 jul 2006.

27. NASSER, Rabih Ali. A OMC e os países em desenvolvimento. São Paulo: Aduaneiras, 2002.

28. NAKAYAMA, Juliana Kiyosen; SÁVIO, Marcelo. Acordo geral sobre comércio de serviços na OMC: considerações. Jus Navigandi, Teresina, ano 6, n. 52, nov. 2001. Disponível em: <http://jus2.uol.com.br/doutrina/texto.asp?id=2302>. Acesso em: \$27 ago. 2006.

29. NOGUEIRA, Saulo P. L. Como derrubar as barreiras internacionais de comércio manual de diplomacia comercial. São Paulo: Lex Editora, 2006. 
30. Organização Mundial de Comércio. Disponível em: 〈http://www.wto.org>. Acesso em: 8 ago 2006.

31. RATTI, Bruno. Comércio internacional e câmbio. 10ª Edição. São Paulo: Aduaneiras, 2004.

32. RANGEL, Vicente Marotta. Direito e relações intermacionais. $5^{\mathrm{a}}$ ed. São Paulo: Revista dos Tribunais, 1997.

33. SACHS, Jeffrey. Tragam o Estado de volta. Exame, São Paulo, p. 114, 15 mar 2006.

34. SOUZA, José Dalmo Silva. Economia descomplicada: terapia de ajustes às dívidas sociais. Rio Grande do Sul: Unijui, 1999.

35. SALVATORE, Dominick. Economia internacional. Rio de Janeiro: LTC, 1998.

36. THORSTENSEN, Vera. OMC - Organização Mundial do Comércio: as regras do comércio internacional e a nova rodada de negociações multilaterais. $2^{\mathrm{a}}$ ed. São Paulo: Aduaneiras, 2001.

37. TOFFLER, Alvin. Powershift. Rio de Janeiro. Rio de Janeiro: Record, 1990.

38. TRIPODI, T.; FELlin, P.; MEYER, H. Análise da pesquisa social. São Paulo: Francisco Alves, 1981.

39. VASQUEZ, José Lopes. Comércio Exterior Brasileiro. $5^{\text {a }}$ Ed. São Paulo: Atlas, 2001. VEIGA, Pedro da Motta. IGLESIA, Roberto Magno. A institucionalidade da política brasileira de comércio exterior. Disponível em: <www.desenvolvimento.gov.br>. Acesso em: 8 ago 2006. 